\title{
BMJ Open Women's experiences of the renewed National Cervical Screening Program in Australia 12 months following implementation: a qualitative study
}

Rachael H Dodd (D), Olivia A Mac, Kirsten J McCaffery

To cite: Dodd RH, Mac OA, McCaffery KJ. Women's experiences of the renewed National Cervical Screening Program in Australia 12 months following implementation: a qualitative study. BMJ Open 2020;10:e039041. doi:10.1136/ bmjopen-2020-039041

- Prepublication history and additional material for this paper are available online. To view these files, please visit the journal online (http://dx.doi org/10.1136/bmjopen-2020039041).

Received 02 April 2020 Revised 19 May 2020 Accepted 04 June 2020
Check for updates

(C) Author(s) (or their employer(s)) 2020. Re-use permitted under CC BY-NC. No commercial re-use. See rights and permissions. Published by BMJ.

Sydney Health Literacy Lab, School of Public Health, The University of Sydney, Sydney, New South Wales, Australia

Correspondence to Dr Rachael H Dodd; rachael.dodd@sydney.edu.au

\section{ABSTRACT}

Objective To explore women's experiences of the renewed National Cervical Screening Program in Australia from the perspective of women who have received different human papillomavirus (HPV) test results. Women aged 25 to 74 are now screened every 5 years with primary HPV screening.

Design Qualitative interview study.

Setting Australia.

Participants Women in Australia aged 25 to 74 who reported participating in cervical screening since December 2017, purposively sampled by test result (HPV positive, HPV negative and HPV status unknown).

Methods 26 interviews with women aged 25 to 74 were conducted and analysed thematically.

Results Three main themes emerged: knowledge and attitudes about the programme changes, information dissemination, the meaning and responses to test results and the new cervical screening test (CST). Some women showed little awareness of the changes, but others understood that HPV is detected earlier than abnormal cells. Some expressed positive attitudes towards the CST and were not anxious about less frequent screening. Most women envisaged the changes would have minimal impact on their screening behaviour. Women mainly wanted more information about the changes and the possible results from the new CST. Overall women could recall their HPV results and understand the implications for future cervical screening. Anxiety about being at 'increased risk' was more apparent in women who were HPV positive without history of abnormal results.

Conclusions Women show some understanding of HPV and the new CST, but more written and public communication about the changes and possible results are warranted. Efforts are needed to ensure that women who are HPV positive without history of abnormal results receive the information needed to alleviate anxiety.

\section{INTRODUCTION}

As cervical cancer prevention strategies such as the human papillomavirus (HPV) vaccination and cervical screening are increasingly successful in reducing HPV infections ${ }^{1}$ and cervical abnormalities, ${ }^{2}$ countries worldwide are looking to switch from primary cytology-based cervical screening to primary

\section{Strengths and limitations of this study}

- The qualitative design enabled us to explore indepth experiences of women residing in Australia who reported cervical screening since implementation of the renewed National Cervical Screening Program and their understanding of the results from the new cervical screening test.

- A major strength is the inclusion of women with a range of test results and provide insight into how much information women perceived they received about the new programme and how they understood their test results.

- Due to the qualitative nature of the study, we cannot express the findings as generalisable across the whole population and the sample was restricted to women who could speak English.

- The method by which women were recruited into the study may reflect women who are more wellinformed and therefore some caution is necessary when applying these findings to the whole population.

HPV-based screening. ${ }^{3-5}$ Australia was one of the first high-income countries to implement primary HPV-based screening in the Renewal of the Australian National Cervical Screening Program (NCSP) in December 2017, where women aged 25 to 74 are now screened every 5 years with primary HPV-based screening. ${ }^{6}$ Although there was an initial announcement of the changes by the Australian government in April 2014, there was no mass awareness campaign to inform the public. Significant publicity of the changes rose in early 2017 following a petition started against the changes.

Prior to the implementation of the Renewal, women were not invited for screening, but screened when due by their primary care provider. Once women had been screened, their details were recorded on their state or territory register and women overdue for screening would receive a reminder 


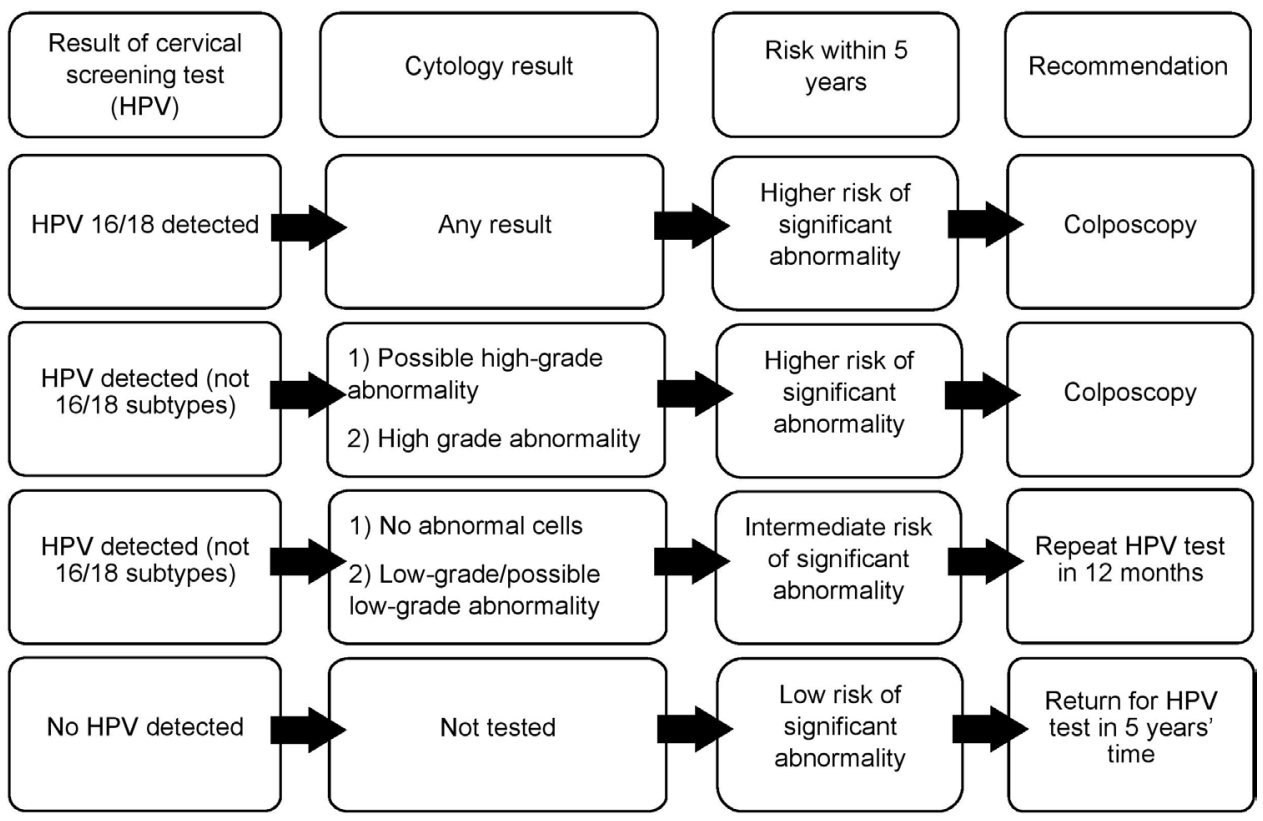

Figure 1 Australian National Cervical Screening Program results pathway. HPV, human papillomavirus.

letter. Since the Renewal, details of women who have been screened will be recorded on the National Cancer Screening Register and they will receive an invitation letter for screening when they are due and reminder letters when they are overdue.

There is no standardised approach in Australia to informing women of their results, which varies by primary care provider. Primary HPV-based screening changes the screening results women receive. In addition to being told their HPV test result (HPV positive/HPV negative), women will also receive information about their risk of a significant cervical abnormality, determined by the subtype of HPV they have (HPV 16/18 or HPV not 16/18 subtype). Women who are HPV negative (HPV-) will be told they are at low risk and are recommended to rescreen in 5 years' time (figure 1). ${ }^{8}$ Women who are HPV positive $(\mathrm{HPV}+)$ will also have a cytology test. HPV+ women, not $16 / 18$ subtype, who have normal cytology or low-grade abnormalities will be informed they are at intermediate risk and will be recommended to rescreen in 12 months' time. Women with any HPV+ resultwho have abnormal cytology will be informed that they are at higher risk and will be referred for a colposcopy. ${ }^{9}$

Previous research has demonstrated a number of negative psychosocial impacts for women testing HPV+ including anxiety and distress, ${ }^{10} 11$ feelings of stigma, embarrassment and confusion, as well as concerns about their sexual relationships in terms of trust, fidelity and blame due to concern about the sexually transmitted nature of HPV. ${ }^{12}$ Findings from our previous study which surveyed over 1000 women in Australia, also showed women who tested HPV+ were more anxious and distressed than those who tested HPV-, ${ }^{13}$ with anxiety scores 10 points higher than those found in a recent English study. ${ }^{5}$
As most research to date has been quantitative and conducted prior to implementing the NCSP changes, there is a need for in-depth qualitative exploration of women's views and experiences of the renewed NCSP in the year since its implementation. Qualitative findings can explore women's first-hand experience of the new programme, and their response to the new test results along with their understanding of what these results mean for them, which may be useful for other countries implementing primary HPV-based screening. This study aimed to explore in-depth women's experiences of the renewed cervical screening programme, from the perspective of women who have received different test results.

\section{MATERIALS AND METHODS \\ Participants and recruitment}

Participants were women residing in Australia who had received cervical screening since the renewal of the NCSP (December 2017). Participants were recruited through a market research company, Dynata during December 2018. Dynata have a database panel of 600000 members in Australia to approach participants who meet the eligibility criteria. Participants listed on their database have already indicated a willingness to participate in online research. Women were directed to a web-link to read the participant invitation statement and provide their written consent to participate (via a tick-box) before completing an online questionnaire eliciting demographic and cervical screening information as well as psychosocial measures. At the end of the survey, women were asked if they would like to participate in a follow-up interview and if yes, asked to leave their contact details so the research team could contact them. 


\begin{tabular}{|c|c|c|c|c|c|c|c|c|}
\hline & \multicolumn{2}{|c|}{ Education } & \multicolumn{4}{|c|}{ Age } & \multicolumn{2}{|c|}{ HPV vaccine } \\
\hline & $\begin{array}{l}\text { No } \\
\text { university }\end{array}$ & $\begin{array}{l}\text { University } \\
\text { or } \\
\text { diploma }\end{array}$ & $<35$ & $36-50$ & $51-65$ & $66+$ & Yes & No \\
\hline \multicolumn{9}{|l|}{$\begin{array}{l}\text { Cervical screening } \\
\text { test result }\end{array}$} \\
\hline \multicolumn{9}{|l|}{ HPV positive ( $n=15)$} \\
\hline Other (HPV+ other risk) & 0 & 6 & 1 & 3 & 1 & 1 & 2 & 4 \\
\hline $\begin{array}{l}\text { Type unknown } \\
\text { (HPV+ type unknown) }\end{array}$ & 2 & 3 & 1 & 1 & 2 & 1 & 2 & 3 \\
\hline HPV negative $(n=8)$ & 2 & 6 & 3 & 1 & 3 & 1 & 2 & 6 \\
\hline $\begin{array}{l}\text { HPV status unknown: don't know/ } \\
\text { unsure }(n=3)\end{array}$ & 2 & 1 & 2 & 0 & 1 & 0 & 2 & 1 \\
\hline
\end{tabular}

NB; numbers total $n$ under each test result across the columns of education, age and HPV vaccine. HPV, human papillomavirus.

Participants received points from Dynata which can be redeemed for items such as gift vouchers, donations to charities or cash. Participants first received points that represented modest compensation for the time spent completing the survey, with further points on completion of an interview.

Participants were purposively sampled from 449 women agreeing to be contacted for interview, to include women from a range of age groups, education and test results (HPV+ 16/18, HPV+ other, HPV-, HPV status unknown; table 1). Of these 449 women, 33 were HPV+, $374 \mathrm{HPV}-$ and 42 didn't know or couldn't remember their result (HPV status unknown). Data collection ceased when no new themes were emerging from the data and therefore saturation was reached. ${ }^{14}$

\section{Procedure}

Semi-structured interviews, using a purpose-designed interview guide informed by a review of previous literature on women's attitudes towards changes to cervical screening programmes, both in Australia ${ }^{715} 16$ and overseas, ${ }^{1718}$ were conducted during December 2018.

The topic guide covered questions regarding attitudes, understanding and confidence, expected impact, understanding of results, any psychosocial impacts and helpful educational and other support resources, in relation to the NCSP changes (see online supplementary information).

Interviews took place over the telephone and lasted between 10 and $27 \mathrm{~min}$. Interviews were audio-recorded and professionally transcribed.

\section{Patient and public involvement}

Patients and the public were not directly involved in the design or planning of the study.

\section{Analysis}

Interviews were analysed using Framework Analysis, an approach well suited to this type of research due to the organisation of data into a thematic framework which then enables views and experiences to be grouped together and comparisons made across participants.

Both RHD and OAM familiarised themselves with the transcripts by reading over all the transcripts and making notes of recurring themes. RHD developed the initial framework using the qualitative package NVivo $11 .{ }^{19}$ The framework was amended through discussions between RHD and OAM and refined with input from KJM. Using NVivo 11, data were summarised and organised into a matrix where each column represented a subtheme and each row a participant. Themes were derived from the data in an inductive process and the topic guide was not used as a reference during the analysis and interpretation of the data. Any disagreements in interpretation were resolved by discussion. The research team members work in the field of public health, with a special interest in reducing overdiagnosis and overtreatment.

\section{RESULTS}

We interviewed 26 women with sample characteristics shown in table 2. Most women in the sample described being regular screeners (every 2 years). Some women in the sample had experienced abnormalities or a diagnosis of HPV previously and so had been monitored more closely than every 2 years under the old programme.

Three main themes emerged from the data: knowledge and attitudes about the changes, information dissemination and focus on meaning of results and the new test.

\section{Knowledge and attitudes about the changes}

Despite being screened under the renewed programme, some women demonstrated a lack of awareness of the changes to the cervical screening programme (Q1; table 3). Women who were knowledgeable about the 
Table 2 Sample characteristics

\begin{tabular}{ll}
\hline & N (\%) \\
\hline HPV status & \\
HPV+ 16/18 & $4(15.4)$ \\
HPV+ other risk & $6(23.1)$ \\
\hline HPV+ type unknown & $5(19.2)$ \\
$\begin{array}{l}\text { HPV negative } \\
\text { HPV status unknown: don't know/unsure } \\
\text { result }\end{array}$ & $3(30.8)$ \\
Age & \\
$<35$ & \\
$36-50$ & $9(34.6)$ \\
$51-65$ & $7(26.9)$ \\
$66+$ & $7(26.9)$ \\
\hline
\end{tabular}

\section{Education}

\begin{tabular}{lr} 
No university & $18(69.2)$ \\
University & $8(30.8)$ \\
\hline Employment & \\
\hline Full-time & $8(30.8)$ \\
\hline Part-time & $7(26.9)$ \\
\hline Retired/studying/other & $11(42.3)$ \\
\hline Born in Australia & \\
Yes & $22(84.6)$ \\
No & $4(15.4)$ \\
Marital status & \\
Single/dating & $5(19.2)$ \\
\hline Married/living with partner & $13(50.0)$ \\
\hline Partnered/not living with partner & $1(3.8)$ \\
\hline Separated or divorced & $6(23.1)$ \\
\hline Widowed & $1(3.8)$ \\
\hline HPV vaccination & \\
\hline Yes & $9(34.6)$ \\
\hline No/don't know & $17(65.3)$ \\
\hline
\end{tabular}

HPV, human papillomavirus.

changes tended to have sought further information and have done their own research $(\mathrm{Q} 2)$.

Those who were aware regarded the main change to be the extended screening interval, from 2 year to 5 years, with a few women understanding that this was due to the change in screening technology (Q3). Some women understood that what is being tested for has changed, with the effectiveness of screening for HPV rather than abnormal cells, noting this was earlier detection (Q4). Overall women noted that the testing procedure was identical to the Pap smear (Q5).

A concern expressed about the extended screening interval was that cancer might develop and be missed in between screens, particularly prominent in women with personal experience of abnormalities (Q6). A few
HPV- women described the need to take responsibility for their own health due to the increased screening interval, which included getting any symptoms which were 'unusual' checked out at the doctor. However, women also expressed positive attitudes including experiencing less anxiety, stress and discomfort due to screening less often. Those women with positive views tended to contextualise these in terms of the new testing technology being more sensitive and more accurate $(\mathrm{Q} 7)$ and this woman explained how she thought the testing process was much easier if you test HPV+ than previously with the Pap smear due to the ability to test the same sample (Q8).

One woman alluded to the potential for overtreatment if screening with this new testing technology continued on a 2 yearly basis, due to the high incidence of HPV and subsequent referrals for colposcopy (Q9).

Some women also related the programme changes back to the HPV vaccination, recognising that uptake of the HPV vaccination should impact rates of HPV and therefore cervical cancer. This helped them make sense of the programme changes and believed it could also help increase uptake of the HPV vaccination (Q10).

For most women, they envisaged that the NCSP changes would have minimal impact on their screening behaviour. The only tangible impact the NCSP changes would have on their screening behaviour would be having to screen less often.

\section{Information dissemination}

\section{Changes to the programme}

The amount of information women described being given about the changes to the cervical screening programme when they attended for screening varied, with women mostly being told about it being a new test and that the screening interval would now be every 5 years. Some women were made aware of the changes through discussions with their general practitioner (GP)/other health professionals; usually these discussions took place in the consultation, when they attended for screening. Most women said that the explanation was brief, but were asked if they had any questions about the changes (Q11). A few women who attended for their Pap smear prior to December 2017, had been advised by their GP to postpone their screen to December 2017, as then they would then enter into the new programme (Q12).

While some women were happy with the amount of information they received and had good experiences (Q13), others described less positive experiences with health professionals when it came to cervical screening, with one woman explaining that she had to go back multiple times as the doctor did not believe she needed to be screened (Q14).

Very few women reported being provided with written information by their GP or other health professional. In terms of preferences for information about the changes to the cervical screening programme, women talked about the need for advertisement on television and in the media to reach a lot of women to encourage them to 
Table 3 Quotes from interviews to support the themes

Code Quote

Knowledge and attitudes about changes

Q1 I did see I think a couple of little pop up things about it and I know that a couple of girls in my social circle have mentioned that the new test was available and it was a 5-year screening, but I haven't seen any other information about what difference it will make. (HPV-, <35 years old, unvaccinated, university degree)

Q2 I spent a couple of hours actually looking into everything I could find. Just even about HPV itself because I didn't understand any of it.

It was really useful ... but I had to actually go looking for it. It wasn't something that was put out there ... If it had been out there it may have been discussed and I might have known a bit more... It would've been good to have been publicly informed in some ways. (HPV+ (type unknown), 36-50years old, unvaccinated, diploma or certificate)

Q3 Well I know that the main change is you only have to go every 5 years and not every 2 years because they've developed a different way to look at the cells or something (HPV+ (not 16/18), <35years old, vaccinated, diploma or certificate)

Q4 From what I understand, the technology is drastically improved which means obviously its better technology and they trust the technology better. I think the fact they're tracking the virus that causes the cancer is really good. (HPV-, 36-50years old, unvaccinated, diploma or certificate)

Q5 I think in all honestly my experience is it's the same ... I can't say I've noticed any change to be honest. (HPV+ 16/18 and CIN1, 36-50years old, unvaccinated, trade apprenticeship)

Q6 My instant reaction is horror because that's a long time without a Pap smear because you don't know what your body is doing. In there if you've got cancer somewhere in that area, it's got 5 years to spread. (HPV+ (type unknown), 66+ years old, unvaccinated, school certificate)

Q7 Well the fact that if it's done every 5 as opposed to 2 then obviously having to go for less testing, is less anxiety and less stress so on that basis that's good ... If I have to only do it once every 5 years it's very positive in my view. I think it will encourage more people to do it because it's not something that you have to do that often. (HPV+ (not 16/18), 36-50years old, unvaccinated, university degree)

Q8 What's easier now is I don't have to come back for another test and wait for a result then be told now you have to go to a specialist. The fact I knew immediately that's what the next step was really good. That was really positive. (HPV+ (type unknown), 36-50years old, unvaccinated, diploma or certificate)

Q9 I do have concerns as to whether the HPV is over testing, are you finding things that are not meant to be there - is it over diagnosis as well which leads to unnecessary treatments, unnecessary follow ups and referrals. That did cross my mind. (HPV+ (not 16/18), 36-50 years old, unvaccinated, university degree)

Q10 Because you're immunising your girls against the HPV they will be less likely to get cervical cancer, which is why they only have to be screened 5 yearly. (HPV-, 36-50 years old, unvaccinated, diploma or certificate)

\section{Information dissemination}

Q11 Just about the difference now that they're testing for the virus that causes the cell changes rather than testing for cell changes, you can catch things earlier and prevent them. (HPV+ (16/18), 36-50years old, unvaccinated, school certificate)

Q12 I was due to have one, I don't know what month it was, last year and she said wait till December because then they've got a new test. I didn't really worry about it - I mean I haven't had any negative (sic) results (ie, abnormal) so she just said in December they're doing it a different way so do you want to wait till December. (HPV-, 51-65years old, unvaccinated, school certificate)

Q13 She explained the process and how the test works and exactly what she does and how they get the samples and how it's tested. I was quite happy with the extent of the information that she provided. It coincided with my understanding of the test and what the results would show or not. (HPV-, <35 years old, vaccinated, higher school certificate)

Q14 I didn't end up getting it that day. Then ... sent out a request to my old postal address, saying that I was on a high priority list to get it done. They called me up and apologised about it ... The Doctor ... she didn't really believe me again so she called up (Path lab) and asked them if I really needed to be there and they said yes, she's on the priority listing or urgent listing. (HPV+ 16/18, <35years old, unvaccinated, diploma or certificate)

Q15 I think there needs to be an ad done about it because it's prevalent it's there every day it's something women have to have done. It's an element that goes around and I think the public need to be more informed. TV ads, radio ads I think, internet ads because younger generation take much more notice of them. (HPV+ (type unknown), 36-50 years old, unvaccinated, diploma or certificate)

Q16 Maybe it could be a brochure and a conversation from your GP or kind of the doctor/gynaecologist whoever you're communicating with so that they can ask questions and then you have some information to go back and read if you want to. I don't know then I suppose on the brochure if there is a phone number for people to call if they have further questions. (HPV+ not 16/18 and normal cytology, 36-50 years old, unvaccinated, university degree)

\section{Meaning of test results and emotional responses to the new test}

Q17 Results, no. They only really call you in for results if something is wrong and they need to discuss it otherwise you don't sort of hear from them. I would've liked just an acknowledgement to say that everything is fine instead of just assuming. Even if it was only a short email or something. (HPV status unknown, 51-65 years old, unvaccinated, no school or other qualifications)

Continued 


\begin{tabular}{|c|c|}
\hline Code & Quote \\
\hline Q18 & $\begin{array}{l}\text { Oh, I was a little bit nervous. I didn't think that I was a high candidate to have issues. Still it's the first time I've done the } \\
\text { test I could've had a dormant virus or something for a few years and not known about it. It was just generally, because I've } \\
\text { never done it, I'm uncertain it might have been an underlying problem I had never known about but it wasn't so that was } \\
\text { good. (HPV-, <35years old, vaccinated, higher school certificate) }\end{array}$ \\
\hline Q19 & $\begin{array}{l}\text { It didn't mean that I would get cancer but I would have a more increased risk and now I would have to have yearly Pap } \\
\text { smears and they will be tested the old way to detect changes in my cells because we know I've already got the HPV virus. } \\
\text { (HPV+ 16/18 and normal cytology, 36-50years old, unvaccinated, school certificate) }\end{array}$ \\
\hline Q20 & $\begin{array}{l}\text { I'm glad nothing is wrong but it's a little daunting knowing I'm in that increased risk group ... Like I said to my husband it's } \\
\text { more when I have my Pap smear every year now rather than not thinking about it because it's been normal for so long, now } \\
\text { that I've got the virus I think I will be a little bit more anxious until I get the result now. (HPV+ 16/18 and negative cytology, } \\
36-50 \text { years old, unvaccinated, school certificate) }\end{array}$ \\
\hline Q21 & $\begin{array}{l}\text { Well I would believe that it would mean I wouldn't need to go back for } 5 \text { years however given that I've had abnormal test } \\
\text { results in the past I think I will probably still get one done } 2 \text { years after that test just to make sure and if that's clear then I } \\
\text { would be reassured I could then go to } 5 \text { yearly screening ... I think I will take myself to another test. (HPV-, <35years old, } \\
\text { unvaccinated, university degree) }\end{array}$ \\
\hline Q22 & $\begin{array}{l}\text { Probably explaining more about it, how you can get it. I think already having the pamphlet what it can turn into, } \\
\text { cervical cancer and things like that. While you're having the Pap smear I think so too and also if you have to go to get a } \\
\text { procedure like a biopsy or whatever just to explain it again. (HPV+ 16/18 and CIN1,36-50years old, unvaccinated, trade } \\
\text { apprenticeship) }\end{array}$ \\
\hline Q23 & $\begin{array}{l}\text { Yeah, I will be making it (appointment) for when the } 12 \text { months is up for sure. Now I have a better understanding I'm } \\
\text { okay with it and going back in } 12 \text { months it's fine. Hopefully it will be gone and if it's not go back in another } 12 \text { months } \\
\text { or whatever the threshold is. My initial reaction was I have to wait } 12 \text { months, I'm going to have to worry about this for } \\
12 \text { months but now I'm okay about it. (HPV+ (not 16/18), <35years old, vaccinated, diploma or certificate) }\end{array}$ \\
\hline Q24 & $\begin{array}{l}\text { Well I would believe that it would mean I wouldn't need to go back for } 5 \text { years however given that I've had abnormal test } \\
\text { results in the past I think I will probably still get one done } 2 \text { years after that test just to make sure and if that's clear then I } \\
\text { would be reassured I could then go to } 5 \text { yearly screening. (HPV-, <35years old, unvaccinated, university degree) }\end{array}$ \\
\hline Q25 & $\begin{array}{l}\text { I hadn't had sex for years ... the diagnosis I got from the Pap smear (is) normally (for) people (who) are sexually active. I } \\
\text { thought it was some kind of an STI and then when I thought about it I thought I hadn't been with anyone for years, how } \\
\text { did I get this unless it's been in the body for years and shown up now. (HPV+ (type unknown), 66+ yearsold, unvaccinated, } \\
\text { school certificate) }\end{array}$ \\
\hline Q26 & $\begin{array}{l}\text { That's how it was explained and then when he was going through the flow charts and stuff about when you get this and } \\
\text { then we have to do this next treatment. (HPV+ (not 16/18) and normal cytology, 36-50years old, university degree) }\end{array}$ \\
\hline Q27 & $\begin{array}{l}\text { She just pretty much said how most people do have the virus; she wasn't particularly good at explaining it. It was just lucky } \\
\text { that I've already been to so many doctors who are better at explaining it so I've got a general understanding. (HPV+ 16/18, } \\
<35 \text { years old, unvaccinated, diploma or certificate) }\end{array}$ \\
\hline
\end{tabular}

GP, general practitioner; HPV, human papillomavirus; STI, sexually transmitted infection.

go for screening, with radio and Internet advertisements more likely to reach younger women (Q15).

Women felt information resources such as a pamphlet containing information about HPV and how common it is, would be useful to refer to as well as communicating it as being 'normal'. Additionally, information on self-care in terms of what to do if something is wrong or what potential symptoms could be, was also perceived as important. Being signposted to a website with information about the changes to the screening programme and the meaning of results, was also suggested.

\section{New results}

When asked if there was anything that would have helped to better understand screening under the revised programme, most women suggested a 'staggering of information' over time, where they would receive information about the changes/possible results prior to screening and then again when receiving the results. Women who tested $\mathrm{HPV}+$ in particular wanted to know about the possible results/referral information prior to screening; women who tested HPV- were more indifferent about receiving information about possible results prior to screening. Information about what the results meant was the main focus of seeking information for these women.

Women acknowledged that too much information can be overwhelming and lead to increased anxiety. Women felt information could accompany the invitation letter or be displayed in waiting rooms, with the combination of a brochure and conversation with a health professional being optimal (Q16).

The key time points identified for information delivery were: (i) prior to screening, when invited; (ii) during screening; (iii) when receiving screening results. Information formats suggested by women included information pamphlets in GP offices, web-links to reputable online sources; and posters in shopping centres/public toilets.

\section{Meaning of test results and emotional responses to the new} test

Women received their screening results in various ways including by letter, over the phone, face-to-face during a 
GP appointment or not hearing anything and assuming everything was ok (Q17). A few women described their anxiety in the time between the test and the results, with one woman expressing this was the first time she'd had the test and so didn't know what to expect (Q18).

Overall women were able to recall their HPV results (positive or negative) and understand the implications these HPV results have for returning for screening in the future. Even among the women who did not know their results, they knew when they were due to have screening again. However, these women did not demonstrate knowledge about the nature of HPV, its transmission and the implications of testing positive (or negative) for HPV and the associated risk of progression to cervical cancer. Some women who were HPV+ did express knowledge that their $\mathrm{HPV}$ result did not mean that cancer is inevitable and that these abnormal cells can resolve by themselves without the need for treatment (Q19).

Higher risk women who had previously had an abnormal Pap smear result and/or already knew their HPV+ status (especially types 16/18) due to persistent infection, were less alarmed about receiving an HPV+ result. Similarly, women who had previously had a normal Pap smear result and received an HPV- result were also not alarmed by this new type of result. However, women who had previously had normal Pap smear results were somewhat anxious if they received HPV+ results (Q20). One woman who tested HPV- but had a previous abnormality would have liked to be tested more frequently (Q21). Those women who received an HPV+ result would have liked their GP/other health professional to have explained the possible results of this test prior to screening, as a means of preparing them $(\mathrm{Q} 22)$.

One of the HPV+ women described how initially she was worried about waiting 12 months after being told she screened positive for HPV, but a better understanding reduced her worry $(\mathrm{Q} 23)$. Some women told to rescreen in 5 years were happy to follow the guidelines and recommendations, whereas others, particularly those with a history of abnormal results, were wanting further reassurance and said they would rescreen more frequently (Q24).

One older woman, who was not aware of the high prevalence of HPV, alluded to the stigma associated with an HPV+ result, however there were few instances of women expressing feelings of stigma about being HPV+ (Q25). Women showed more limited understanding of accompanying cytology changes; especially among women with normal cytology and low-grade abnormalities. Women with high-grade abnormalities had better understanding, mainly because they had a persistent form of HPV and had previously returned abnormal results and/or had also been referred to a gynaecologist for a subsequent colposcopy. Only a couple of women recalled their level of risk (eg, intermediate risk) for cervical cancer.

Women who were HPV+ talked about their understanding and experiences of the new testing pathway, with one woman describing how the doctor explained it to her using the flowcharts (Q26).

There were some women who felt that healthcare professionals had not adequately explained their results to them. Some women felt the information was not made relevant to them or was too clinical, and that they wanted to be given more details with their results. These women conducted their own research online to find out more about HPV and what their results meant (Q27).

\section{DISCUSSION}

The study findings contribute to our understanding of women's experiences of the deintensified cervical screening programme in Australia and provide us with insight into how women have interpreted communication of their test results. Overall, women showed limited knowledge of the changes to the NCSP, but demonstrated understanding about what the results meant for them and their future screening. There was high variability in how the results were communicated to women by their GP/other health professional. Some women reported positive experiences of communication which provided reassurance and aided good understanding of the changes and implications of results, while others reported poor communication of results by their GP/other health professional and felt they had to independently search for further information. The impact of HPV + results appeared greater in women who had previously had normal Pap smear results. Encouragingly, women envisaged that the changes to the NCSP would have minimal impact on their own screening behaviour. A few women were concerned about changes to the programme leading to missing cancers and getting lost in the system if they moved interstate. These findings mirror those from previous research. ${ }^{720}$

Women in this sample were mainly positive about the changes to the programme, reflected in comments about the new cervical screening test and perceived the test to be more accurate and effective than the Pap smear. This perhaps reflects a trust in decision-makers, that despite some negative press surrounding the changes, women in this sample trusted that the changes had been made for the better and this was reinforced for some when they were advised by their GP to wait for the new programme to be implemented.

It was evident that women still lacked knowledge about HPV and its transmission, particularly in women who were HPV-, and so there is still a great need for community education surrounding cervical screening and HPV. Linking the HPV vaccination to the changes made to the screening programme, gave women a tangible way in which to understand reasons for the 5-year interval being safe. This could be a good strategy to target both mothers and their daughters to educate them about the importance of cervical screening and how advances in technology has enabled us to now screen primarily for the HPV infection.

Although this sample of women mainly reported being told in their GP consultation when they attended for 
screening about the changes in the test and the screening interval, most indicated that they would have liked to have received some written information and also seen some public advertisements about the programme changes, supporting our previous findings. ${ }^{21}$ Women also wanted written information about the test results and expressed the importance that this is consistent across the programme. In addition, how women receive their results should also be standardised, as women in this sample described multiple ways of receiving their results (eg, phone, person, letter). Some women in this sample reported that they did not know or remember their test results. Our own survey data has shown anxiety and distress were higher in women who did not know their results compared with those who were HPV-. ${ }^{13}$ The recommendations provided by the women in this sample for information delivery to be staged across the screening journey, from prior to screening to receiving the results, are important to consider when implementing a new screening test to help women's understanding of both the reasons for the new test and what the results of the new test mean for them. Women have been shown to prefer active or shared decision-making approaches regarding the follow-up of abnormal test results, ${ }^{22}$ so it is important women understand what these results mean for them.

Encouragingly, women reported that their doctors communicated with them about the new test and what this now checks for, with women showing an understanding behind the reason for the change in test. This is important as our previous research showed that communicating to women about the change in test can then help provide reassurance and understanding to women about some of the other changes to the programme. ${ }^{21}$

The psychosocial impact of screening and test results was evident across the sample, particularly with women screened HPV+. When worry and anxiety were expressed by these women, this was mostly related to testing, results and the extended screening interval. A focus needs to be given to information provision for those women who are HPV+ and who have not experienced abnormal results in the past. It is important that they receive the information they need to alleviate anxiety as these women demonstrated greater anxiety than women who were HPV+ with experience of previous abnormalities. Women with previous abnormalities were less alarmed by their results due to their previous experience and having a greater knowledge of the system, but those who screen HPV- who have a history of previous abnormalities may prefer to be screened more frequently.

Encouragingly, there was a good understanding among women who were HPV+ that cancer was not inevitable and that some cell changes might resolve without the need for treatment, demonstrating good communication from health professionals. This is particularly encouraging given around $8 \%$ of women $(n=195606)$ tested HPV+ in the first 6 months of the renewed programme. ${ }^{23}$ Of important note is that this, combined with healthcare providers not adhering to the guidelines, has consequently resulted in the increase in number of colposcopy referrals being much greater than expected. ${ }^{24}$ This holds implications for an increased number of women referred for colposcopy and experiencing long wait times, as awaiting to undergo colposcopy has been shown to increase anxiety levels. ${ }^{25}$

Clear messages to women about the reasons for a change in test, as well as information which normalises HPV and explains what their test results mean for them, are important to communicate and provide reassurance. These messages could be in the form of written or verbal communication, with the need for women testing HPV+ for the first time to receive individualised messages which acknowledge their previous normal test results.

To the best of our knowledge, this is the first study exploring the experiences of women receiving different results after receiving primary HPV screening as part of the National Cervical Screening Programme. The qualitative design enabled us to explore in-depth experiences of women residing in Australia who reported cervical screening since implementation of the renewed NCSP, and their understanding of the results from the new cervical screening test. These findings provide insight into how much information women perceived they received about the new programme and how they understood their test results. Due to the qualitative nature of the study, the aim was not to produce findings which are generalisable across the whole population, but to provide some insight across a purposively collected sample of women who received a range of test results from the renewed cervical screening programme. Most women in the sample were regular screeners and so may not reflect the experiences of women who were previous non-attenders or irregular screeners in the old NCSP and have now had screening under the renewed NCSP. The sample was restricted to women who could speak English.

\section{CONCLUSIONS}

Despite women demonstrating an understanding about the new cervical screening test, more written information and public communication about the changes and possible results are warranted. In particular, efforts are needed to ensure women who are HPV+ with no history of abnormal results receive the information they need to alleviate anxiety. Tailored information could take into consideration women's previous cervical screening results and risk for a significant cervical abnormality.

Acknowledgements We thank Dynata for recruitment services, Alana Fisher for her input and support with data collection and all study participants. We thank the Wiser Healthcare patient partner committee for comments on the design and findings of this research during presentations of the work at Wiser Healthcare National meetings.

Contributors RHD: Conceptualisation, Data curation, Formal analysis, Investigation, Methodology, Project administration, Writing - Original draft preparation. OAM: Formal analysis, Writing - Reviewing and Editing. KJM: Conceptualisation, Methodology, Funding acquisition, Formal analysis, Validation, Writing - Reviewing and Editing. All authors contributed to the interpretation of the analysis and critically revised the manuscript.

Funding This work was supported by a National Health and Medical Research Council Programme Grant (APP1113532). RHD is supported by a University of Sydney Fellowship (197589). 
Competing interests None declared.

Patient and public involvement Patients and/or the public were not involved in the design, or conduct, or reporting, or dissemination plans of this research.

Patient consent for publication Not required.

Ethics approval This study was approved by The University of Sydney Human Ethics Committee (2018/836).

Provenance and peer review Not commissioned; externally peer reviewed.

Data availability statement Data are available upon reasonable request. Data availability: The data sets generated and/or analysed during the study are available from the corresponding author on reasonable request.

Open access This is an open access article distributed in accordance with the Creative Commons Attribution Non Commercial (CC BY-NC 4.0) license, which permits others to distribute, remix, adapt, build upon this work non-commercially, and license their derivative works on different terms, provided the original work is properly cited, appropriate credit is given, any changes made indicated, and the use is non-commercial. See: http://creativecommons.org/licenses/by-nc/4.0/.

\section{ORCID iD}

Rachael H Dodd http://orcid.org/0000-0002-8080-6359

\section{REFERENCES}

1 Machalek DA, Garland SM, Brotherton JML, et al. Very low prevalence of vaccine human papillomavirus types among 18- to 35-year old Australian women 9 years following implementation of vaccination. J Infect Dis 2018;217:1590-600.

2 Australian Institute of Health and Welfare. Cervical screening in Australia, 2019

3 American Cancer Society. The American cancer society guidelines for the prevention and early detection of cervical cancer, 2018. Available: https://www.cancer.org/cancer/cervical-cancer/preventionand-early-detection/cervical-cancer-screening-guidelines.html [Accessed 20 June 2019].

4 Polman NJ, Snijders PJF, Kenter GG, et al. HPV-based cervical screening: rationale, expectations and future perspectives of the new Dutch screening programme. Prev Med 2019;119:108-17.

5 McBride E, Marlow LAV, Forster AS, et al. Anxiety and distress following receipt of results from routine HPV primary testing in cervical screening: the psychological impact of primary screening (PIPs) study. Int J Cancer 2020;146:2113-2121.

6 Medical Services Advisory Committee. National cervical screening program renewal: evidence review (assessment report), 2013.

7 Obermair HM, Dodd RH, Bonner $\mathrm{C}$, Jansen J, et al. 'It has saved thousands of lives, so why change it?' content analysis of objections to cervical screening programme changes in Australia. BMJ Open 2018;8:e019171.

8 Canfell K, Hammond I, Saville M, Cancer Council Australia Cervical Cancer Screening Guidelines Working Party. National cervical screening program: guidelines for the management of screendetected abnormalities, screening in specific populations and investigation of abnormal vaginal bleed, 2018. Available: https://wiki. cancer.org.au/australiawiki/index.php?oldid=190197 [Accessed 27 Mar 2019].

9 Anderson L, Saville M, Wright G. Cancer council Australia cervical cancer screening guidelines working party, 2018. Available: https:// wiki.cancer.org.au/australia/Guidelines:Cervical_cancer/Screening/ Sample_cervical_screening_reports

10 McCaffery K, Waller J, Forrest S, et al. Testing positive for human papillomavirus in routine cervical screening: examination of psychosocial impact. BJOG 2004;111:1437-43.

11 McCaffery K, Waller J, Nazroo J, et al. Social and psychological impact of HPV testing in cervical screening: a qualitative study. Sex Transm Infect 2006;82:169-74.

12 McCaffery K, Forrest S, Waller J, et al. Attitudes towards HPV testing: a qualitative study of beliefs among Indian, Pakistani, African-Caribbean and white British women in the UK. $\mathrm{Br} J$ Cancer 2003;88:42-6.

13 Dodd $\mathrm{RH}$, Mac O, Brotherton JML, et al. Levels of anxiety and distress following receipt of positive screening tests in Australia's HPV-based cervical screening programme: a cross-sectional survey. Sex Transm Infect 2020;96:166-72.

14 Guest G, Bunce A, Johnson L. How many interviews are enough? an experiment with data saturation and variability. Field methods 2006;18:59-82

15 Jayasinghe Y, Rangiah C, Gorelik A, et al. Primary HPV DNA based cervical cancer screening at 25 years: views of young Australian women aged 16-28 years. J Clin Virol 2016;76:S74-80.

16 Scalzo K, Mullins R. The recommended interval for cervical cancer screening: Victorian women's attitudes to an extended interval. Aust N Z J Public Health 2015;39:153-6.

17 Ogilvie GS, Smith LW, van Niekerk D, et al. Correlates of women's intentions to be screened for human papillomavirus for cervical cancer screening with an extended interval. BMC Public Health 2016;16:213.

18 Ogilvie GS, Smith LW, van Niekerk DJ, et al. Women's intentions to receive cervical cancer screening with primary human papillomavirus testing. Int J Cancer 2013;133:2934-43.

19 QSR. NVivo qualitative data analysis software version 11. QSR International Pty Ltd, 2015.

20 Dodd $\mathrm{RH}$, Obermair HM, McCaffery KJ. A thematic analysis of attitudes toward changes to cervical screening in Australia. JMIR Cancer 2019;5:e12307-9.

21 Dodd RH, Nickel B, Wortley S, et al. Examining the information needed for acceptance of deintensified screening programmes: qualitative focus groups about cervical screening in Australia. BMJ Open 2019;9:e029319.

22 Dieng M, Trevena L, Turner RM, et al. What Australian women want and when they want it: cervical screening testing preferences, decision-making styles and information needs. Health Expect 2013;16:177-88.

23 Machalek DA, Roberts JM, Garland SM, et al. Routine cervical screening by primary HPV testing: early findings in the renewed national cervical screening program. Med $J$ Aust 2019;211:mja2:113-9.

24 Smith M, Hammond I, Saville M. Lessons from the renewal of the National cervical screening program in Australia. Public Health Res Pract 2019;29:1-6.

25 Rogstad KE. The psychological impact of abnormal cytology and colposcopy. BJOG 2002;109:364-8. 